\section{Primary myocardial diffuse large B cell lymphoma. Report of one case}

\author{
LUIS F. RUBALCAVA LARA ${ }^{1}$, ALEJANDRO AVILES-SALAS ${ }^{2}$, \\ MYRNA CANDELARIA ${ }^{3}$
}

\begin{abstract}
Primary myocardial involvement of Diffuse Large B-Cell lymphoma is extremely rare, accounting for $0.5 \%$ of all lymphomas. We report a 65 -year-old male, presenting with an acute cardiac tamponade, which was drained. A pericardial window with myocardial biopsy was carried out, disclosing a diffuse large B cell lymphoma. He received 6 cycles of rituximab, cyclophosphamide, vincristine, and prednisone (R-CVP), without response. Finally, a palliative chemotherapy with gemcitabine plus oxaliplatin was prescribed.
\end{abstract}

(Rev Med Chile 2021; 149: 1231-1235)

Key words: Drug Therapy, Combination; Drug Therapy; Lymphoma.

\section{Linfoma difuso de células grandes miocárdico primario. Informe de un caso}

El linfoma difuso de células grandes $B$, primario del miocardio es muy raro. Presentamos un varón de 65 años que se presentó con un taponamiento cardíaco agudo que fue drenado. La biopsia miocárdica un mostró linfoma difuso de células grandes B, primario de miocardio. El paciente recibió 6 ciclos de quimioterapia con rituximab, ciclofosfamida, vincristina y prednisona sin respuesta. Finalmente se optó por una quimioterapia paliativa con gemcitabina yoxaliplatino.

Palabras clave: Linfoma; Quimioterapia; Terapia Combinada.

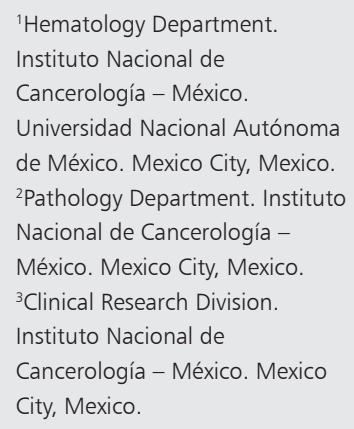

Conflict of interest. All authors declare no conflicts of interest. Ethical considerations: The patient signed Informed consent.

Recibido el 7 de julio de 2021, aceptado el 28 de septiembre de 2021.

\section{Correspondence to:}

Myrna Candelaria

Clinical Research Division.

Av. San Fernando 22, Belisario

Domínguez Secc 16, Tlalpan,

14080 Ciudad de México, CDMX. candelariahmgloria@gmail.com.
$\mathrm{T}$ The primary cardiac lymphoma was initially characterized in 1978, when McAllister et al. assigned it as a distinct pathological categorization ${ }^{1}$. After that, two criteria were used: the strict one defines it as a non-Hodgkin lymphoma that originates and involves only in the heart or pericardium ${ }^{2}$, and the loose one, which defines it as a non-Hodgkin's lymphoma with cardiac manifestations associated when a bulk of tumor is found in the heart ${ }^{3}$. The incidence is extremely rare and variate according to the series, they account for $1-1.3 \%$ of all cardiac tumors and $0.5 \%$ of all the extranodal lymphomas ${ }^{4,5}$. Reports of primary cardiac lymphoma are sporadic, and series usually include a few numbers of patients, in a 60 -year span during the last century approximately 197 were reported ${ }^{6}$.

The most frequent histology of primary cardiac lymphomas is diffuse Large B-cell lymphoma (DLBCL), but there are also reports of Burkitt-like lymphomas ${ }^{7,8}$ and T-cell lymphoma, small lymphocytic lymphoma and plasmablastic lymphoma ${ }^{3}$. Since it is a very rare presentation, and none guidelines regarding the treatment, 
we considered of interest to report a case with primary myocardial DLBCL.

\section{Case presentation}

A 65-year male patient with a prior history of pericarditis, treated during 4 months with riphampycin/ pyrazinamide/ isoniazid/ ethambutol, was transferred to a hospital because of dyspnea, anterior chest pain and leg swelling restarted along with episodes of syncope, During the clinical approach, the electrocardiogram (EKG) presented with non-sinusal rhythm, auricle-ventricle $(\mathrm{AV})$ dissociation, blockade of the left His bundle and complete AV blockade. The initial echocardiogram showed a $40 \%$ ejection fraction, pericardial effusion with collapse of the right auricle. He improved after a pacemaker and pericardiocentesis. The control echocardiogram documented an increase of the ejection fraction to $60 \%$, left ventricle with concentric hypertrophy and without hypokinesia, dilation of both auricles, mild aortic and mitral regurgitation and an infiltrative tumor which involved the anterior wall of the left ventricle. The thorax computed tomography (CT) showed a tumor infiltrating the anterior left auricle, interatrial septum, anterior wall of the left and right ventricle and in the adjacent pericardium. A pericardial window with myocardial biopsy, was done. The biopsy and immunohistopatological analysis diagnosed a diffuse large $B$ cell lymphoma with CD20+, CD10+, BCL-2+, BCL-6+, MUM-1+, Ki67 70\% (Figure 1). A total-body Computed Tomography-Positron Emission Tomography (CT-PET) was performed, with final report of a solid irregular tumor, with poorly defined edges, occupying the ventricular walls (predominantly the left ventricle), with extension to the pericardium, with a SUVmax of 22.6. No other hypermetabolic sites were identified. The bone marrow biopsy and lumbar puncture discarded lymphoma infiltration. Serologic tests for HIV, hepatits $B$ virus, and hepatits $C$ virus were negative. Due to the high risk of myocardial rupture a fractioned first cycle was implanted, with 5 days of dexamethasone and in the fifth day co-infusion of vincristine ( $2 \mathrm{mg}$ total dose). At the day +11 , rituximab and cyclophosphamide were infused. We decided not to use doxorubicin, to keep the cardiac adverse events at minimum. After three cycles of R-CVP (rituximab [375 mg/m2 +1], cyclophosphamide $[750 \mathrm{mg} / \mathrm{m} 2+1]$, vincristine [ $2 \mathrm{mg}+1]$ and prednisone [ $100 \mathrm{mg}$, daily +1 to $+5]$ ), a partial response was documented by CT. However, at the end-of-treatment, the CT -PET demonstrated progressive disease, with an increase of the myocardial tumor with extension into the mediastinum, with a SUVmax 22. The patient refused an intensive chemotherapy treatment option and opted for palliative chemotherapy with Gemcitabine plus oxiplatin.

\section{Discussion}

The incidence of primary myocardial lymphoma is extremely rare and constitutes $1-1.3 \%$ of all cardiac tumors and $0.5 \%$ of all the extranodal lymphomas ${ }^{4,5}$. The prototypical patient is a male of approximately 60 years old, as was this patient ${ }^{9}$. Approximately $10 \%$ will present distant infiltration or extension to local lymph nodes ${ }^{5}$. However, in this case none nodal involvement was documented. The immunocompromised state is considered a risk factor for primary extranodal DLBCL, and up to $41 \%$ are HIV positive 3 . Interestingly, this case had none immunosuppressor comorbidity.

This patient had also an infrequent myocardial infiltration, since his major involvement was the left auricle, interatrial septum, anterior wall of the left and right ventricle and in the adjacent pericardium and the most common localization is the right atrium (92\%), and the infiltration of the left side of the heart is usually associated with affection in the right side and only $7 \%$ are reported to be isolated left sided ${ }^{4}$.

Although the use of pericardial fluid cytology has a sensibility for infiltration of $88 \%$, but the specificity is low and atypical lymphocytes can also be detected in reactive pericarditis or other cardiac neoplasms ${ }^{7}$, for this reason the use of immunocytochemical staining is recommended. The two procedures with an almost $100 \%$ success rate in sample biopsy are: thoracotomy (open or with mediastinoscopy), as was done in this patient, and transesophageal echocardiography-guided trans jugular biopsy ${ }^{5}$.

The use of echocardiography for tumor detection has a sensibility $55 \%$ for the transthoracic 


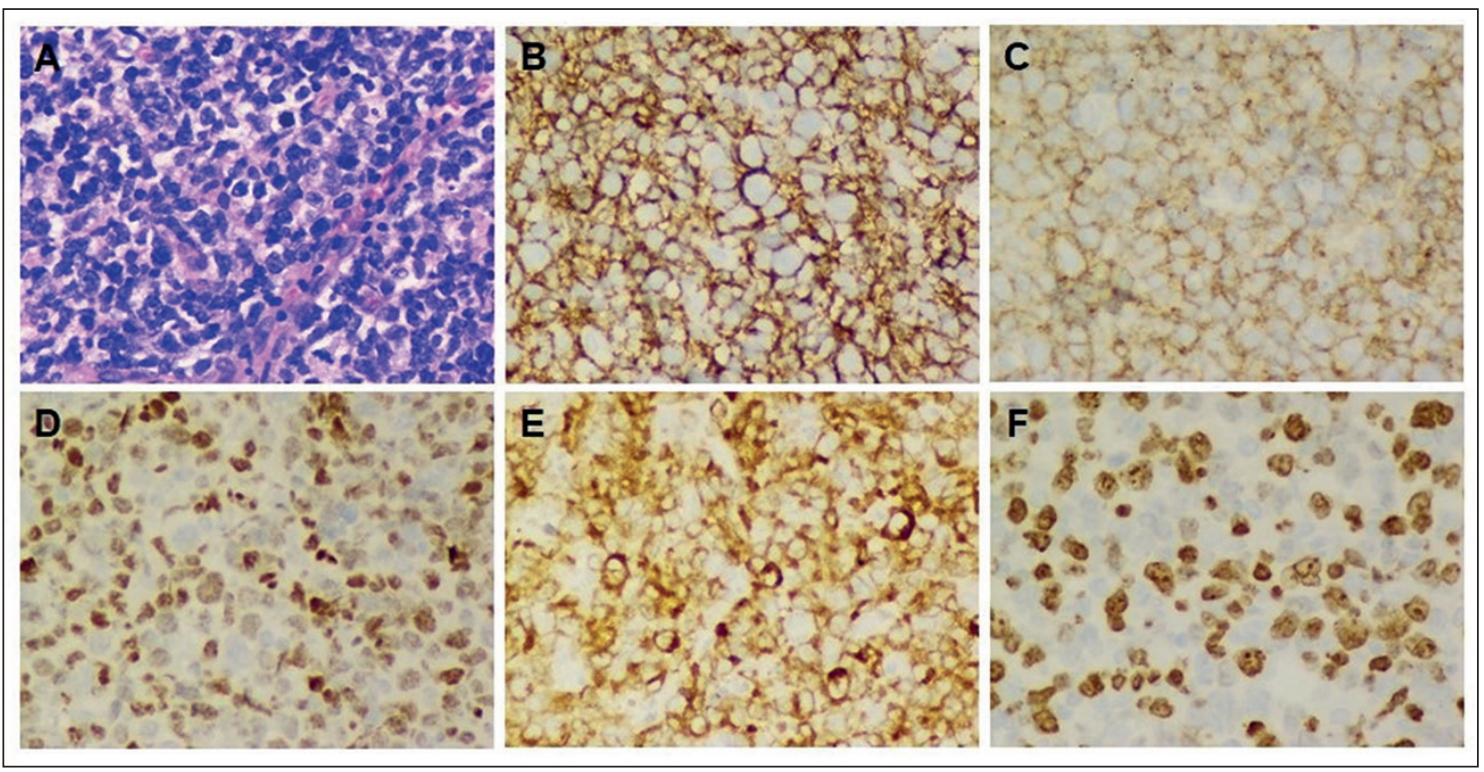

Figure 1. Germinal-center, Diffuse Large B-cell lymphoma. Neoplastic cells have ovoid nuclei, fine chromatine, apparent nucleoli, and poorly defined cytoplasm; HE staining, $400 \times$ (A). The neoplastic cells were positive for CD20 (B), CD10 (C), Bcl-6 (D), BCL-2 (E), and Ki67 in $70 \%$ (F); immunohistochemical technique, $400 \mathrm{X}$.

mode and $97 \%$ in the transesophageal ${ }^{8}$. In a CT scan the bulk of the tumor usually appears hypoattenuated compared with healthy myocardium, its real usefulness in the initial screening of cardiac tumor is in the detection/delineation of extracardial involvement ${ }^{9}$. The cardiac magnetic resonance is considered the most cost-effective image study for diagnosis and surveillance of treatment response ${ }^{9}$. The usual finding is a poorly defined lesion with hypointense on T1-weighted images and isointense T2-weighted images ${ }^{10}$. The use of 18-FDG-PET shows an increased tracer uptake of the cardiac mass in all cases and allows for identification of extracardiac lesions ${ }^{11}$.

The low incidence of this malignancy makes it problematic to establish gold standard treatment guidelines, the most common modality was the use of anthracycline-based chemoterapy along with immunotherapy but use of surgical resection and radiotherapy have been performed. In Petrich et al. $89 \%$ of the patients received CHOP regimen, with a treatment related mortality (TRM) of $10 \%$ and an overall response (OOR) of $79 \%{ }^{3}$. The use of R-CEOP was used in large sized tumor without any reported adverse events, the change of doxorubicin for epirubicin was to avoid cardiotoxicity ${ }^{9}$. Carras et al. has also reported other schemas, as R-miniCHOP, CEOP and "GELA Regimen"11.

The fear of myocardial rupture due to chemotherapy is commonly mentioned in different publications, but the reported cases that present this complication is minimal. Nevertheless, several clinicians have tried dose modified regimens to prevent complications, especially in large sized tumors that compromise the hemodynamic system. In this case, we did a pre-phase with dexamethasone, and vincristine as has been described for aggressive tumors, also, since this patient had developed an acute tamponade, the anthracycline was suppressed to avoid major cardiovascular complications. Other authors have recommended to start with a $50 \%$ dose reduction for the first 2 cycles, after size-reduction is objectively demonstrated and myocardial rupture risk decreases the dose is then up-scaled ${ }^{12-14}$.

The prognosis is worse compared to other subtypes of diffuse large B cell lymphoma. Petrich et al. reported that $57 \%$ of the cases died, being heart failure during the treatment the most 
common cause of death ${ }^{3}$. The presence of extra-cardiac extension, immunocompromise, left ventricle affection and arrythmias are associated with poor prognosis. In particular, in this case a pacemarker was required, anthracyclines were avoided, and the first cycle was fraccionated in order to avoid cardiovascular complications. The presence of left ventricular involvement and arrythmia seem to be the most important risk factors, a median survival of 1 month was been reported for both, which is significantly lower median survival compared to those without left ventricle involvement ( 22 months) or arrythmias (6 months) $)^{15}$. In larger series the ORR is $70 \%$ with a CR of approximately $60 \%$ of cases and a median OS of $12^{3}$ to 62 months ${ }^{11}$. Even in non-immunocompromised patients the CR is lower compared to non-cardiac B cell lymphoma, in Chin et al. only $61 \%$ achieved $\mathrm{CR}^{16}$.

Of the $60 \%$ patients that will achieve CR, approximately $50 \%$ will relapse (the majority in the first 5 months $)^{7}$. The use of second and third lines was dismal for these patients. In patients who relapsed, and a second biopsy was made a high percentage presented CMYC mutations ${ }^{17}$. A higher relapse rate has been observed in patients receiving dose adapted $\mathrm{CHOP}$ regimens compared to intensive regimens (ACE, ACVBP, COPADM) which could give a treatment related relapse risk factor.

\section{Conclusion}

The primary myocardial diffuse large B cell lymphoma is a rare entity, which has been poorly reported. The lack of a standardized guideline or even expert opinion makes the treatment a challenge, so the treatment most be individualized according to the case and experience in each center.

\section{References}

1. McAllister HA, Other cardiac tumors. En: McAllisterHA, Fenoglio JJ. Tumors of the cardiovascular system. Atlas of tumor Pathology, $2^{\text {nd }}$ series, fasicle 15, Washington, DC: Armed Forces Institute of Pathology, 1978; 99-100.

2. Cairns P, Butany J, Fulop J, Rakowski H, Hassaram S.
Cardiac presentation of non-Hodgkin's lymphoma. Arch Pathol Lab Med 1987; 111 (1): 80-3.

3. Petrich A, Cho SI, Billet H. Primary cardiac lymphoma: an analysis of presentation, treatment and outcome patterns. Cancer 2011; 117 (3): 581-9. doi: 10.1002/ cncr.25444.

4. Flox-Camacho A, Hernández-Hernández F, SalgueroBodes R, Sánchez-Pérez I, Carbonell-Porras A, et al. Primary cardiac lymphoma: diagnosis by transjugular biopsy. Rev Esp Cardio. 2003; 56 (11): 1141-4. doi: 10.1016/s0300-8932(03)77026-2.

5. Ceresoli GL, Ferreri AJ, Bucci E, Ripa C, Ponzoni M, Villa E. Primary cardiac lymphoma in immunocompetent patients. Diagnostic and therapeutic management. Cancer 1997; 80 (8): 1497-506. doi: 10.1002/(sici)10970142(19971015)80:8<1497::aid-cncr18>3.0.co;2-0.

6. Chen F. Primary cardiac lymphoma with unusual presentation: A report of two cases. Mol Clin Oncol 2017; 6(3):311-4.

7. Springgs AI, Vanhegan RI. Cytological diagnosis of lymphoma in serous effusions. J Clin Pathol 1981; 34 (12):1311-25. doi: 10.1136/jcp.34.12.1311.

8. Faganello G, Belham M, Thaman R, Blundell J, Eller T, Wilde P. A case of primary cardiac lymphoma: Analysis of the role of echocardiography in early diagnosis. Echocardiography 2007; 24: 889-92.

9. Gowda RM, Khan IA. Clinical perspectives of primary cardiac lymphoma. Angiology 2003; 54 (5): 599-604. doi: $10.1177 / 000331970305400510$.

10. Ryu SJ, Choi BW, Choe Ko. CT and MR findings of primary cardiac lymphoma: Report upon 2 cases and review. Yonsei Med J 2001; 42 (4): 451-6.

11. Carras S, Berger F, Chalabreyesse L, Callet-Bauchut E. Primary cardiac lymphoma: diagnosis, treatment and outcome in a modern series. Hematol Oncol 2016; 35 (4): 510-9. doi: 10.1002/hon.2301.

12. Beckwith C, Butera J, Sadaniantz A, King TC, Fingleton J, Rosmarin AG. Diagnosis in oncology. Case 1: primary transmural cardiac lymphoma. J Clin Oncol 2000; 18 (9): 1996-7. doi: 10.1200/JCO.2000.18.9.1996.

13. Dawson MA, Mariani J, Taylor A, Koulouris G, Avery S. The succesful treatment of primary cardiac lymphoma with a dose-dense schedule of rituximab plus CHOP. Ann Oncol 2006; 17 (1): 176-7. doi: 10.1093/annonc/ mdj005

14. Almehisen R, Almohaissen M, Yousef H. Cardiac involment in disseminated diffuse large-B cell lymphoma, successful management with chemotherapy dose reduction guided by cardiac imaging: A case report and review of literature. Word J Clin Cases 2019; 7 (2): 191-202. doi: 10.12998/wjcc.v7.i2.191. 
15. Khanjan S, Shemisa K. A low and slow approach to successful medial treatment of primary cardia lymphoma. Cardiovasc Diagn Ther 2014; 4 (3): 270-3. doi: 10.3978/j.issn.2223-3652.2014.04.01.

16. Chin JY, Chung MH, Kim JJ, Lee JH, Kim JH, Maeng $\mathrm{IH}$, et al. Extensive primary cardiac lymphoma diagnosed by percutaneous endomyocardial biopsy. J Car- diovasc Ultrasound 2009; 17 (4): 141-4. doi: 10.4250/ jcu.2009.17.4.14.

17. Zhou K, Xu D, Cao Y, Wang J, Yang Y, Huang M. $\mathrm{C}-\mathrm{MYC}$ aberrations as prognostic factors in diffuse large B-cell lymphoma: a meta-analysis of epidemiological studies. PLoS One. 2014; 9(4): e95020. doi: 10.1371/ journal.pone.0095020.

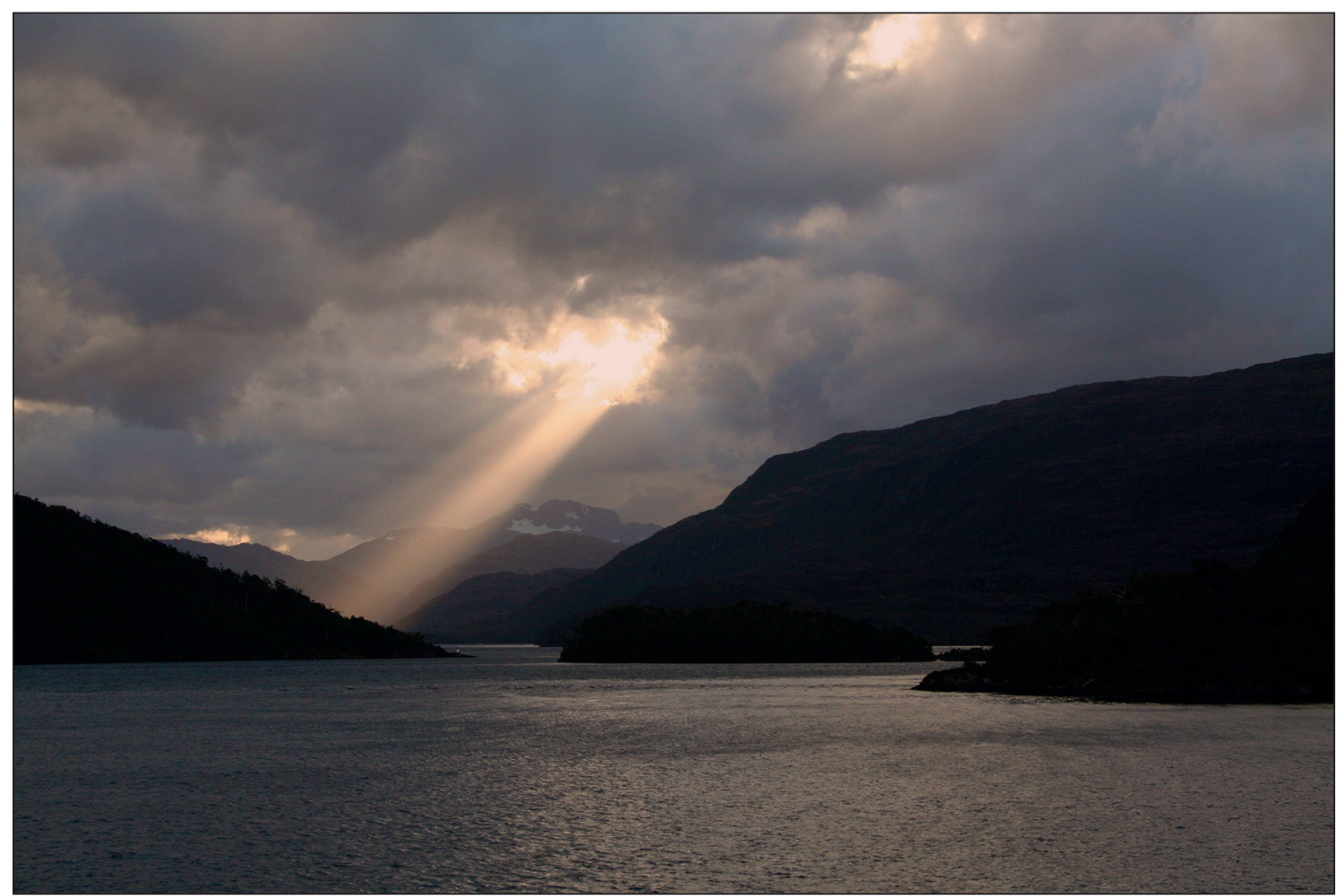

Campos de Hielo Sur: Canal Kirke, Ultima Esperanza, Región de Magallanes. Dr. Jorge Sapunar Zenteno 